\title{
The Integration of Chinese National Piano Works in Piano Education
}

\author{
Qiong Zhu \\ Yangtze University, Jingzhou, 434000, China
}

\begin{abstract}
This paper first describes the significance and principles of integrating Chinese national piano works into piano education, and then expounds the specific measures from the aspects of works appreciation, innovative teaching contents, stimulating students' emotions and making reasonable plans.
\end{abstract}

Key words: piano education; national piano; integrated into

\section{Introduction}

Piano itself is a western musical instrument. Since it was introduced into China, piano education still has a strong dependence on western music in terms of teaching content, system and thinking, while ignoring the infiltration of Chinese traditional music in piano teaching, thus lacking its distinctive characteristics. This kind of teaching method will make the piano knowledge and skills mastered by students relatively one-sided, without a certain degree of creativity. The integration of Chinese piano education works in piano education can make piano education more Chinese characteristics, so that students can feel the charm of national culture.

\section{The Significance of Integrating Piano Education into Chinese National Piano Works}

Piano education relies too much on western music education and ignores the integration of Chinese traditional culture in piano education, which leads to students' persistent imitation in learning and lack of innovative consciousness and ability. Therefore, it is of great significance to integrate Chinese national piano works into piano education, which is mainly reflected in the following aspects: first, to promote the sinicized development of piano education. On the basis of western piano works, many Chinese piano works integrate Chinese traditional culture and national characteristics. Chinese national piano works contain extremely rich Chinese culture, which is not only a formal innovation, but also the presentation and inheritance of traditional culture. The integration of Chinese national piano works into piano education can fundamentally promote the localization of piano education in China. The other is to improve students' piano performance. The integration of Chinese national piano works can effectively improve students' piano performance quality. In music teaching, the piano as a major instrument has received great attention. Compared with western music, Chinese folk music has more diversified presentation forms. Teachers should pay attention to the growth and development of students when teaching, so that students can master more comprehensive knowledge. The third is to pay attention to the inheritance of traditional culture. Chinese national works contain extremely rich traditional culture, and the integration of works into piano education is actually a kind of inheritance of traditional culture.In teaching, every student is the inheritor of the traditional culture and receives and absorbs the traditional culture actively under the guidance of teachers.

Copyright (C) 2019 by author(s) and Frontier Scientific Research Publishing Inc.

This work is licensed under the Creative Commons Attribution International License (CC BY 4.0).

$\mathrm{http}$ //creativecommons.org/licenses/by/4.0/ 


\section{Principles of Integrating Chinese National Piano Works into Piano Education}

The integration of Chinese national piano works into piano education should follow the relevant principles, so as to give full play to the role of Chinese national works in piano education. The principles are as follows:

\subsection{Progressive principle}

In school teaching, students from freshman to senior are usually divided into three stages: elective, general and major. Therefore, when choosing Chinese national piano works, different grades, basic level and different learning methods should be taken into full consideration. According to the difficulty of the work, the principle from easy to difficult should be followed, and the rationality and system should be guaranteed.According to different levels of students need to choose different ethnic piano works to teach, so as to meet the personalized learning needs of different levels of students.

\subsection{Principle of comprehensiveness}

In the process of selecting and editing piano works, it is necessary to make scientific configuration of different genres, themes, styles and types of works according to time and composer's works, instead of selecting only one style of works. Only by mastering comprehensiveness can students fully feel the similarities and differences in the piano works, so as to improve their performance ability and piano artistic accomplishment.

\section{The Integration of Chinese National Piano Works in Piano Education}

\subsection{Appreciate works}

To integrate national piano works into piano education, students can try to appreciate Chinese national piano works first, and then gradually accept and understand them. Piano education in China mainly originates from the west, and the teaching materials also focus on the inheritance, inheritance and imitation of western culture, which mostly reflects the characteristics of a foreign culture. In this case, many students always believe that excellent piano works come from the west when they first learn about piano works and play. The only real piano artists are Beethoven, Mozart, Chopin, Debussy and so on. Therefore, in the current process of piano education, teachers should pay special attention to the integration of Chinese national piano works. In practical teaching, teachers should start with students' music appreciation ability, strengthen students' identification of national culture, and be able to recognize Chinese piano art, so that students can generate national pride. For students, if they can analyze and appreciate the style characteristics of works, they can master and understand the style, aesthetics and expressive force of piano works, so that students can make relatively objective appreciation of national piano works.

\subsection{Innovative teaching content}

To integrate national piano works into piano education, it is necessary to realize innovation and optimization in educational content. The integration of national piano works in piano education is not only a process of introducing them into classroom teaching, but also a process of filling the shortage of teaching materials in practice. In this process, teachers need to select appropriate piano works to integrate into the classroom teaching according to the teaching content and the real situation of students, so as to promote the modernization and sinicization of piano education. Teachers should solve the shortcomings and related problems in the traditional teaching methods and timely fill and solve. For example, traditional Chinese music is very different from western music in playing skills. In view of this, teachers should timely supplement relevant knowledge for students, so as to realize the modernization of teaching development, give students inspiration. Many excellent Chinese national piano works are based on folk music or classical music, so when playing these music, we should try to ensure the charm and style of the original repertoire, and give full play to the characteristics of the piano, so as to expand the charm of piano performance. 


\subsection{Arouse students' emotion}

When playing Chinese national piano works, it shows more of an emotional resonance, and each piece is closely connected with the social environment at that time. In this context, students need to have a deep understanding of the connotation and grasp the rich emotions contained in the learning of music. For example, when learning the song "autumn moon on the lake", we need to integrate the development of traditional Chinese music. If you cannot understand this logic and emotion, you will not be able to feel the true meaning and connotation of music, and you will not be able to play works full of emotion, which need to be paid real attention to and attached importance to in teaching. In actual teaching, teachers need to precisely locate the teaching focus, so that students can deeply feel the real artistic conception of music, feel the emotions of composers in the arrangement of music, so as to identify and perceive the emotions of music. Only in this way can students fully integrate into the piano repertoire when playing, so as to play and present more perfect piano music that can infect the audience's emotions, so that they can feel the charm of national piano works.

\subsection{Develop a reasonable piano skills plan}

It is an effective measure to integrate Chinese piano music into piano teaching to make a reasonable national piano skill plan. In the development and planning of the work, the following aspects need to be implemented: first, the implementation of the theoretical course should be integrated into the appreciation of ethnic works; meanwhile, the development of the skill class should also try to quantify the quantity and quality of piano works; Second, in the development of piano works, we should pay attention to the diversity of forms and differences in styles. In this process, teachers should not only strengthen students' cognition, understanding and performance ability of national piano works, but also give students more inspiration. For example, in the performance of piano grace notes, the western countries play according to the rules. However, there is no grace note standard in Chinese national works, which can only be flexibly controlled according to the performer's understanding of music. For example, in such piano works as "er quan ying yue" and "white bird chao feng", there are timbres that imitate national instruments. The combination of virtual and real timbres and the combination of light and shade requires the performers to present through different ways of touching keys. It can be seen from this that when providing different performance and expression techniques for Chinese national piano works, it is still necessary to make in-depth exploration and research in the actual teaching and develop a reasonable piano skill training plan.

\section{Conclusions}

Folk music is the essence of the Chinese nation, which is very important for the development of national culture and national spirit. The integration of national piano works into piano education can promote the inheritance of traditional culture in Chinese piano education and improve students' piano artistic accomplishment. In practical teaching, by guiding students to appreciate national piano works, stimulating students' emotions, innovating teaching contents, and formulating reasonable piano skill plans, we can effectively integrate national piano works into piano education, thus making piano teaching sinicized and characteristic.

\section{References}

[1] Ma Y.Q.(2018). Analysis on the Application of Chinese Piano Works in Piano Teaching in Universities. Northern Music, 18, 131-132.

[2] Lu Y.R.(2018). On the Application of Chinese Piano Works in Piano Teaching in Universities. Drama House, 36, 163-164.

[3] Huang Z.Z.(2019). The Application of Chinese Piano Works in Piano Teaching in Universities. Northern Music, 8, $45-47$. 